\title{
Atrial Fibrillation, Heart Failure with Impaired Ejection Fraction and Natriuretic Peptides
}

\section{Ebru İpek Türkoğlu1, ๑ Emine Çiğdem Kırçiçeği Çiçekdağ2}

1İzmir Kemalpaşa State Hospital, Clinic of Cardiology, İzmir, Turkey

2İzmir Kemalpaşa State Hospital, Clinic of Anesthesiology and Reanimation, İzmir, Turkey

\begin{abstract}
Objectives: Atrial fibrillation (AF) is frequent in clinical practice and its relationship with heart failure (HF) is well known. The present study investigated clinical and biochemical characteristics and N-terminal pro-B type natriuretic peptide (NT-proBNP) levels of patients with AF and $\mathrm{HF}$ with impaired left ventricle ejection fraction in a closed cohort.
\end{abstract}

Materials and Methods: Patients who had AF, left ventricle ejection fraction (LVEF) $<50 \%$ and who had a NT-proBNP measurement in the stable phase of HF, who applied to the İzmir Kemalpaşa State Hospital's cardiology clinic between January and June 2018 were enrolled. Characteristics of 137 patients and the correlation of the change in creatine, glomerular filtration rate (GFR), and NT-proBNP to the clinical factors were investigated.

Results: Mean age, $\mathrm{LVEF}, \mathrm{CHA}_{2} \mathrm{DS}_{2}$ and $\mathrm{CHA}_{2} \mathrm{DS}_{2} \mathrm{VASc}$ scores were $71.8 \pm 9.1$ years, $46.9 \pm 5.3 \%, 3.2 \pm 1.3$ and $4.7 \pm 1.3$ respectively in the study group. The median NTproBNP was $1553.00 \mathrm{pg} / \mathrm{mL}$ in stable phase of HF. Elevated
NT-proBNP in decompensated phase was present in 32 patients and the median was $2944.50 \mathrm{pg} / \mathrm{mL}$. Initial GFR was correlated positively with hemoglobin but strongly negatively with age, $\mathrm{CHA}_{2} \mathrm{DS}_{2}$ and $\mathrm{CHA}_{2} \mathrm{DS}_{2} \mathrm{VASc}$ scores. NT-proBNP was correlated strongly positively with $\mathrm{CHA}_{2} \mathrm{DS}_{2} \mathrm{VASc}$ and systolic pulmonary artery pressure and negatively with LVEF as expected.

Conclusion: Both of $\mathrm{AF}$ and $\mathrm{HF}$ are related to an increase of NT-proBNP level. Present study suggests a median $92.05 \%$ increase compared to stable phase level in NT-proBNP is related to decompensation. This finding emphasizes the importance of level of stable phase-NT-proBNP in patients with $\mathrm{AF}$ for the diagnosis of decompensation, because of no consensus on upper limit of NT-proBNP in patients with AF while the knowledge of higher levels is not new. Also, the relationship between GFR and $\mathrm{CHA}_{2} \mathrm{DS}_{2}, \mathrm{CHA}_{2} \mathrm{DS}_{2} \mathrm{VASc}$ scores implicates careful GFR monitoring in patients with higher scores to avoid improper drug doses such as NOAC's.

Keywords: Atrial fibrillation, heart failure, NT-proBNP

Address for Correspondence: Ebru İpek Türkoğlu, İzmir Kemalpaşa State Hospital, Clinic of Cardiology, İzmir, Turkey Phone: +90 2328787575 e-mail: dripek73@yahoo.com ORCID: orcid.org/0000-0002-2321-8868 Received: 17.03.2020 Accepted: 16.04.2020

Cite this article as: Türkoğlu Eİ, Kırçiçeği Çiçekdağ EÇ. Atrial Fibrillation, Heart Failure with Impaired Ejection Fraction and Natriuretic Peptides. EJCM 2020;8(2):72-77.

DOI: $10.32596 /$ ejcm.galenos.2020.03.014

${ }^{\circ}$ Copyright 2020 by Heart and Health Foundation of Turkey (TÜSAV) / E Journal of Cardiovascular Medicine published by Galenos Publishing House. 


\section{Introduction}

Atrial fibrillation (AF) is the most common arrhythmia in cardiology practice. In Europe and United States of America, one of four adults is to be expected to develop $\mathrm{AF}$ in lifetime. The predicted boost of patients with $\mathrm{AF}$ is multifactorial. The increase of AF-related diseases such as hypertension (HT), heart failure (HF), coronary artery disease (CAD) and improved life expectancy are important factors but increased clinical sensibility to diagnose and treat $\mathrm{AF}$ has an outstanding value. Hence, $\mathrm{AF}$ is related to all-cause mortality and morbidity such as HF and stroke in both genders, a great effort is given to prevent undesirable events $^{(1)}$. Another important issue is the cost of AF, which rises depending on AF-related complications such as stroke if AF is not treated properly ${ }^{(2)}$. Many patients have both $\mathrm{AF}$ and $\mathrm{HF}$ and these diseases can augment each other in multi different ways. AF is related to an increased mortality and worse prognosis in both HF with impaired left ventricle ejection fraction (LVEF) and preserved LVEF. Although natriuretic peptides (NP) are essential in the diagnosis and follow-up of HF, to interpret their levels in the presence of AF may be challenging because of their elevated levels even in the absence of HF. Yet, there is no consensus for the upper normal limit in the presence of $\mathrm{AF}^{(3,4)}$. In the present study, we aimed to investigate characteristics and NT-proBNP levels in stable HF patients who have AF with impaired LVEF in our closed cohort.

\section{Material and Methods}

Outpatient data of İzmir Kemalpaşa State Hospital's Clinic of Cardiology was reviewed retrospectively for a given time through the hospital record system (HRS) PROBEL. Patients were selected through their diagnostic ICD-10 codes. Patients diagnosed with AF were searched. The diagnosis of AF was made with an electrocardiogram, which demonstrates the typical pattern of AF in accord to European recommendations. After that, the patient records about their history, laboratory and imaging results were reviewed. Since the hospital was the only healthcare facility in a cohort with more than 100,000 people and AF was considered as a chronic disease, data were interpreted as closed cohort data. AF-patients with a LVEF $<50 \%$ and having a NT-proBNP measurement during stable phase of HF were included. Stable phase of HF was defined according to European guideline as a treated patient with symptoms and signs of HF, who remained unchanged for a minimum one-month period. Prosthetic heart valves, moderate to severe mitral stenosis and end stage renal disease requiring hemodialysis were considered as the exclusion criteria. Medications such as oral anticoagulant (OAC) agents and treatment adherence were controlled via social security system through the Internet. LVEF measurements were made with 2D transthoracic echocardiogram with the modified Simpson's rule according to European recommendations.

The ethic approval of the present the study was obtained on 14.11.2018 from the University of Health Sciences Turkey, İzmir Tepecik Health Practice and Research Center, with the decision number: 2018/13-13. All the authors had no conflict of interest.

NT-proBNP was the choice of natriuretic peptide because of its more stable profile and the measurements were made with Cobas ${ }^{\circledR}$ system using Elecsys proBNP II from Roche Diagnostics GmbH.

\section{Statistical Analysis}

In the statistical analysis, data were given as mean \pm standard deviation when the variables distributed normally and as median if they did not in the statistical analysis. Categorical variables were defined with frequencies and percentages. IBM SPSS-22 program was used for analysis.

\section{Results}

After screening the patient-data between January and June 2018, 137 patients with AF and LVEF $<50 \%$ with NT-proBNP measurement during stable phase of HF were included. The mean age was $71.8 \pm 9.1$ years. Gender pattern was slightly female dominant $(\mathrm{n}=79$ female (57.7\%) vs $\mathrm{n}=58$ male (42.3\%)). Comorbid diseases such as CAD, 34.3\% ( $\mathrm{n}=47)$, Diabetes Mellitus, 31.4\% ( $\mathrm{n}=43)$, 
HT, 89.8\% ( $\mathrm{n}=123)$, cerebrovascular event (CVE), 21.9\% $(\mathrm{n}=30)$ and embolic event (peripheral arterial or venous), $2.9 \%(n=4)$ were present in the study group in given frequencies. Other diseases such as malignancy, dementia, other neurological disorders (Parkinson's or epilepsy) and thyroid disease were present at the rates of $5.1 \%(n=7)$, $3.6 \%(\mathrm{n}=5), 5.1 \%(\mathrm{n}=7)$ and $11.7 \%(\mathrm{n}=16)$, respectively. AF diagnosis was paroxysmal in 12 patients (8.8\%) and persistent in 125 patients $(91.2 \%)$ while only eight patients were in sinus rhythm during recruiting. The mean follow-up duration of the study group in the clinic was $2.50 \pm 1.23$ years. OAC treatment was present in 135 of 137 (98.5\%) patients while $36.8 \%$ of patients were taking OAC treatment for more than 3 years. Only $8.7 \%$ of the study group was taking warfarin hence remaining 91.3\% was on non-vitamin K antagonist OAC (NOAC) treatment. Any bleeding was reported in 32 patients (23.4\%), which was defined minor in $20(62.5 \%)$ patients and major (a drop more than $2 \mathrm{~g} / \mathrm{dL}$ in haemoglobin or any bleeding required transfusion) in 12 patients $(37.5 \%)$ in accord to International Society of Thrombosis and Haemostasis (ISTH), but there was no report on life-threating or critical organ bleeding or death. Through the HRS PROBEL, the initial creatine and glomerular filtration rates (GFR) before OAC therapy and the actual (last) creatine and GFR measurements were found. GRF was calculated via the Cockcroft-Gault method. While all of patients had NT-proBNP level in stable phase of HF, 32 patients had also NT-proBNP measurement in decompensated phase of HF. Descriptive demographics of study group are given in Table 1.

The study group consisted of elderly patients with impaired LVEF and high $\mathrm{CHA}_{2} \mathrm{DS}_{2}$ VASc score as seen in Table 1. The mean GFR of the group was $<60 \mathrm{~mL} / \mathrm{min}$, which is also another high-risk predictor. The initial and actual creatine and GFR, stable and decompensated NTproBNP levels and their alterations are given in Table 2. There was a decrease in GFR during the follow-up with a mean duration of $2.50 \pm 1.23$ years, which is attributed to aging and sarcopenia related to the HF, while creatine levels stayed similar. The median NT-proBNP level of AF patients with impaired LVEF in stable phase was 1553.00 $\mathrm{pg} / \mathrm{mL}$, which may be considered very high for a stable patient, while median NT-proBNP was $2944.50 \mathrm{pg} / \mathrm{mL}$ in decompansation, which is almost twice as high according to the latest recommendations. Lastly, the correlation between some important clinical parameters and creatine, GFR, NT-proBNP and their changes were investigated. The correlation for baseline GFR and haemoglobin was positive, while for age, $\mathrm{CHA}_{2} \mathrm{DS}_{2}$ and $\mathrm{CHA}_{2} \mathrm{DS}_{2} \mathrm{VASc}$ scores negative. NT-proBNP was correlated with

Table 1. Descriptive demographics

\begin{tabular}{|l|l|l|}
\hline & $\mathbf{n}$ & Mean \pm SD \\
\hline Age & 137 & $71.82 \pm 9.17$ years \\
\hline CHA $_{2}$ DS $_{2}$ VASc & 137 & $3.23 \pm 1.33$ \\
\hline Systolic BP & 137 & $4.70 \pm 1.36$ \\
\hline Diastolic BP & 137 & $143.07 \pm 23.83 \mathrm{mmHg}$ \\
\hline Heart rate & 137 & $84.10 \pm 13.48 \mathrm{mmHg}$ \\
\hline LVEF & 137 & $87.12 \pm 19.76 \mathrm{bpm}$ \\
\hline LA diameter & 137 & $46.99 \pm 5.32 \%$ \\
\hline Tricuspid Annulus & 137 & $51.44 \pm 5.05 \mathrm{~mm}$ \\
\hline SPAP & 124 & $39.76 \pm 4.20 \mathrm{~mm}$ \\
\hline Hemoglobin & 137 & $41.10 \pm 8.46 \mathrm{mmHg}$ \\
\hline Fasting glucose & 137 & $12.77 \pm 2.15 \mathrm{~g} / \mathrm{dL}$ \\
\hline HDL & 137 & $113.3 \pm 31.5 \mathrm{mg} / \mathrm{dL}$ \\
\hline LDL & 135 & $50.59 \pm 13.13 \mathrm{mg} / \mathrm{dL}$ \\
\hline TG & 135 & $97.09 \pm 34.25 \mathrm{mg} / \mathrm{dL}$ \\
\hline Urea & 135 & $130.30 \pm 80.62 \mathrm{mg} / \mathrm{dL}$ \\
\hline Creatine & 137 & $44.98 \pm 17.70 \mathrm{mg} / \mathrm{dL}$ \\
\hline Na & 137 & $1.19 \pm 0.29 \mathrm{mg} / \mathrm{dL}$ \\
\hline K & 137 & $141.66 \pm 3.25 \mathrm{mmol} / \mathrm{L}$ \\
\hline Uric Acid & 136 & $4.53 \pm 0.50 \mathrm{mmol} / \mathrm{L}$ \\
\hline GFR & 110 & $7.25 \pm 2.03 \mathrm{mg} / \mathrm{dL}$ \\
\hline NT-proBNP & 137 & $56.14 \pm 16.34$ \\
\hline TSH & 137 & $1553.00 \mathrm{pg} / \mathrm{mL}$ \\
\hline & 137 & $1.30 \mathrm{mU} / \mathrm{L}$ \\
\hline & & $($ median$)$ \\
\hline
\end{tabular}

BP: Blood pressure, LVEF: Left ventricle ejection fraction, LA: Left atrium, SPAP Systolic pulmonary artery pressure, HDL: High density lipoprotein, LDL: Low density lipoprotein, TG: Triglyceride, Na: Sodium, K: Potassium, GFR: Glomerular filtration rate, TSH: Thyroid stimulant hormone, NT-proBNP: N-terminal pro-B type natriuretic peptide, SD: Standard deviation, $n$ : Number

Baseline demographics of study population is given in table1. Median levels of NT-proBNP is used because of its non-normal distribution 
$\mathrm{CHA}_{2} \mathrm{DS}_{2}$ VASc and systolic pulmonary artery pressure (SPAP) positively and with LVEF negatively. The change in NT-proBNP showed a positive correlation with systolic blood pressure and SPAP.

\section{Discussion}

Patients with AF constitute an increasing part of daily cardiology practice nowadays. Treatment with OAC in $\mathrm{AF}$ is crucial to prevent ischemic complications such as embolic stroke anticoagulation management in this population became easier with NOAC in last years. Accompanying $\mathrm{HF}$ is another important issue in $\mathrm{AF}$ patients for both patients and physicians in decision-

Table 2. Changes during follow-up

\begin{tabular}{|c|c|c|}
\hline & $\mathbf{n}$ & Mean \pm SD \\
\hline Initial creatine & 52 & $1.19 \pm 0.40 \mathrm{mg} / \mathrm{dL}$ \\
\hline Actual creatine & 137 & $1.19 \pm 0.29 \mathrm{mg} / \mathrm{dL}$ \\
\hline$\Delta$ Creatine & 52 & $-0.01 \pm 0.42 \mathrm{mg} / \mathrm{dL}$ \\
\hline Initial GFR & 52 & $62.29 \pm 16.11$ \\
\hline Actual GFR & 137 & $56.14 \pm 16.34$ \\
\hline$\Delta \mathbf{G F R}$ & 52 & $-7.71 \pm 12.9$ \\
\hline Stable phase NT-proBNP & 137 & $1553.00 \mathrm{pg} / \mathrm{mL}$ (median) \\
\hline Decompensated NT-proBNP & 32 & 2944.50 pg/mL (median) \\
\hline$\Delta$ NT-proBNP (\%) & 32 & $\begin{array}{l}1524.50 \mathrm{pg} / \mathrm{mL}(92.05) \\
\text { (median) }\end{array}$ \\
\hline \multicolumn{3}{|c|}{$\begin{array}{l}\text { GFR: Glomerular filtration rate, NT-proBNP: N-terminal pro-B type } \\
\text { natriuretic peptide, SD: Standard deviation, } n \text { : Number } \\
\Delta: \text { Change } \\
\text { Hence NT-proBNP is distributed non-normally, median values are used }\end{array}$} \\
\hline
\end{tabular}

making process. HF may be either with preserved or impaired LVEF. Hence HF classification is made through the LVEF and defined as reduced (LVEF $<40 \%$ ), mildly reduced (LVEF between 40 and 50\%) and preserved ( $\mathrm{LVEF} \geq 50 \%$ ) ejection fraction $\mathrm{HF}$, the present study excluded patients with preserved LVEF and focused on group with impaired $\mathrm{LVEF}^{(3)}$.

The growing experience with AF and HF patients underlined the importance of renal functions. Either relatively nephrotoxic effect of drugs used in the treatment of HF such as diuretics and Renin- Angiotensin System (RAS) inhibitors or progressive nature of HF with a wellknown relation with kidneys necessitates to monitor renal functions. Renal functions are crucial in patients with AF taking NOAC because the relation between bleeding and erroneous over-dosed NOACs is well-known ${ }^{(5)}$. The present study has shown that GFR is decreasing in patients with AF and HF with impaired LVEF within years even creatine levels of these patients stay similar. Decreasing of GFR according to Cockcroft-Gault method may be related to advancing age and decreasing body weight while serum creatine stays similar. Loosing body weight in HF should not be evaluated only as volume loss, but also the catabolic process of HF, known as sarcopenia, should be taken into consideration and weight fluctuation in these patients should be taken seriously. A strong negative correlation between GFR and age is expected but the

Table 3. Correlation of renal functions and NT-proBNP with some clinical parameters

\begin{tabular}{|c|c|c|c|c|c|c|c|}
\hline & & Creatine & $\Delta$ Creatine & GFR & $\Delta \mathbf{G F R}$ & NT-proBNP & $\Delta$ NT-proBNP \\
\hline Age & $r$ & 0.053 & -0.192 & $-0.622^{* *}$ & -0.092 & $0.212^{*}$ & 0.274 \\
\hline $\mathrm{CHA}_{2} \mathrm{DS}_{2}$ & $r$ & 0.062 & $-0.299^{*}$ & $-0.232^{\star *}$ & -0.090 & 0.156 & 0.291 \\
\hline Systolic BP & $r$ & 0.001 & $0.337^{*}$ & 0.018 & -0.126 & 0.004 & $0.474^{* *}$ \\
\hline Heart rate & $r$ & -0.048 & -0.201 & 0.056 & 0.042 & $0.178^{*}$ & 0.065 \\
\hline SPAP & $r$ & -0.023 & 0.183 & -0.076 & 0.004 & $0.330^{* *}$ & $0.468^{* *}$ \\
\hline Hemoglobin & $r$ & -0.063 & -0.007 & $0.308^{* *}$ & -0.016 & $-0.206^{*}$ & -0.125 \\
\hline
\end{tabular}


negative strong correlation with $\mathrm{CHA}_{2} \mathrm{DS}_{2}$ and $\mathrm{CHA}_{2} \mathrm{DS}_{2}$ VASc scores make close follow-up of renal functions essential in high-score patients to avoid overdosing. The positive correlation of GFR and hemoglobin indicates the clinical importance of anemia, which is not uncommon in HF patients. The presence of anemia in this group of patients should also raise attention for careful follow up renal function to avoid misdosing.

$\mathrm{AF}$ and $\mathrm{HF}$ augment each other in multi-different ways. To interpret the NP in this group of patients is especially difficult hence both diseases are related to increased levels of NP( ${ }^{(6)}$. NPs are very important in the diagnosis of acute HF. Different cut-off values are proposed for different NPs and even different societies suggest different cutoff values for the same NP. Until a recent time, European guideline recommended NT-proBNP $>125 \mathrm{pg} / \mathrm{mL}$ for the diagnosis of acute HF hence American recommendation was between 300 and $1800 \mathrm{pg} / \mathrm{mL}$ based on particular age groups and clinical presentations ${ }^{(3,7-10)}$. Very recently, HF study group of European Society of Cardiology published a position paper on NP's and updated recommendations for upper limits of NT-proBNP to diagnose acute HF. The new European position paper put forward the data of PRIDE study and updated its recommendations similar to the American recommendations according to agespecific upper limits ${ }^{(8,9,11)}$. The last European guideline recommends NT-proBNP $>450 \mathrm{pg} / \mathrm{mL}$ if the patient is younger than 50 years, $>900 \mathrm{pg} / \mathrm{mL}$ if between 50 and 75 years and $>1800 \mathrm{pg} / \mathrm{mL}$ if older than 75 years to diagnose acute $\mathrm{HF}^{(11)}$. With the growing number of $\mathrm{AF}$ patients, the interpretation of NP has become a hotspot nowadays, searching for the inclusion cut-off's in this group. Very recently, Santema and colleagues published an original article using the data of BIOSTAT-CHF trial. They compared biomarker profiles such as NTproBNP of patients with HF comparing AF versus sinus rhythm and reduced versus preserved $\mathrm{LVEF}^{(12)}$. While studying patients with reduced LVEF according to the last European definition as LVEF $<40 \%$, patients with mildly reduced (40-49\%) LVEF are excluded from the analysis, which represents an important group especially in AF. To overcome this dilemma, we included all the HF patients even reduced and mildly reduced by the definition, and named the group as "impaired" LVEF, which can be used to define patients excepting the ones with preserved ejection fraction HF. Santema et al. ${ }^{(12)}$ showed a median of NT-proBNP as $3093 \mathrm{pg} / \mathrm{mL}$ in AF with reduced LVEF (a mean $\pm \mathrm{SD}$ of $36 \pm 14 \%$ ) during decompensation, which is very similar to our findings. Although elevated levels of NT-proBNP is expected in AF, there is no consensus about the upper normal limit and the interpretation is far more difficult in the presence of HF with impaired LVEF without knowing how much increase is related to $\mathrm{AF}$ and how much to reduced ejection fraction. The most important contribution of the present study is the value of NT-proBNP level in stable phase of HF with impaired LVEF in the presence of AF while there is no consensus on upper limits. Besides the present study underlines the importance of stable phase NT-proBNP in follow-up such high risk patients. Also, the present study suggests that decompensation is related to a median $92.05 \%$ increase in NT-proBNP in this special population.

\section{Study Limitatons}

There are some important limitations in our study. Retrospective single center design is an important limitation. Also, a control group in sinus rhythm with similar LVEF and HF could unveil the effect of AF on NTproBNP levels far better. Because of archive screening design, some adverse events like bleeding or embolic event may be overlooked. Despite these limitations, our study presents useful information for clinical practice, hence our data represents real-world closed cohort data for a long follow-up duration, which was more than 3 years in $36.8 \%$ of patients.

\section{Conclusion}

Our study suggests the importance of NT-proBNP levels in patients with stable phase of HF with impaired ejection fraction and $\mathrm{AF}$, who represent a high-risk group in clinical practice. As renal function test, GFR should be 
monitored closely, but not serum creatine, especially in patients with anemia and high $\mathrm{CHA}_{2} \mathrm{DS}_{2}$ and $\mathrm{CHA}_{2} \mathrm{DS}_{2}$ VASc scores to avoid erroneously over-dosing, which may cause adverse events.

\section{Acknowledgements}

We are thankful to Ömer Kaplan for his great effort on statistical analysis of the study.

\section{Ethics}

Ethics Committee Approval: The ethic approval of the present the study was obtained on 14. 11.2018 from the University of Health Sciences Turkey, İzmir Tepecik Health Practice and Research Center, with the decision number: 2018/13-13.

Informed Consent: Retrospective study.

Peer-review: Internally and externally peer-reviewed.

\section{Authorship Contributions}

Concept: E.İ.T., Design: E.İ.T., E.Ç.K.Ç., Data Collection or Processing: E.İ.T., E.Ç.K.Ç., Analysis or Interpretation: E.İ.T., E.Ç.K.Ç., Literature Search: E.İ.T., Writing: E.İ.T., E.Ç.K.Ç.

Conflict of Interest: All the authors had no conflict of interest.

Financial Disclosure: The authors declared that this study received no financial support.

\section{References}

1. Kirchof P, Benussi S. Kotecha D, Ahlsson A, Atar D, Casadei B, et al. The Task Force fort he management of atrial fibrillation of the European Society of Cardiology (ESC). 2016 ESC Guidelines for the management of atrial fibrillation developed in collaboration with EACTS. Eur Heart J 2016; 37 : 2893-962.

2. Wodchis WP, Bhatia RS, Leblanc K, Meshkat N, Morra D. A review of the cost of atrial fibrillation. Value Health 2012;15:240-8.

3. Ponikowski P, Voors AA, Anker SD, Bueno H, Cleland JGF, Coats JGS, et al. The Task Force for the diagnosis and treatment of acute and chronic heart failure of the European Society of Cardiology (ESC). 2016 ESC Guidelines for the diagnosis and the treatment of acute and chronic heart failure. 2016;37: 2129-200.

4. Lip Gy, Heinzel FR, Gaita F, Juanatey RJG, Le Heuzey JY, Potpara T, et al. European Heart Rhythm Association /Heart Failure Assosiation joint consensus document on arrhythmias in heart failure, endorsed by the Heart Rhythm Society and the Asia Pacific Heart Rhythm Society. Europace 2016;18:12-36.

5. Yao X, Shah ND, Sangaralingham LR, Gersh BJ, Noseworthy PA. Nonvitamin $\mathrm{K}$ antagonist oral anticoagulant dosing in patients with atrial fibrillation and renal dysfunction. JACC 2017;69: 2779-90.

6. Lam CSP, Riensta M, Tay WT, Liu LCY, Hummel YM, van der Meer P, et al. Atrial fibrllation in heart failure with preserved ejection fraction. JACC: Heart Failure 2017;5:92-8

7. Kim HN, Januzzi JL Jr. Natriuretic peptide testing in heart failure. Circulation 2011;123:2015-19.

8. Januzzi JL Jr, Camargo CA, Anwaruddin S, et al. The N-terminal pro-BNP investigation of dyspnea in the emergency department (PRIDE) study. Am J Cardiol. 2005;95:948-54.

9. Januzzi JL, van Kimmenade R, Lainchbury J, Bayes-Genis A, OrdonezLlanos J, Santalo-Bel M, et al. NT-proBNP testing for diagnosis and shortterm prognosis in acute destabilized heart failure: an international pooled analysis of 1256 patients The International Collaborative of NT-proBNP Study. Eur Heart J 2006;27:330-7.

10. Brunner-La Rocca H-P, Sanders-van Wijk S. Natriuretic peptides in chronic heart failure. Cardiac Fail Rev 2019;5:44-9.

11. Mueller C, McDonald K, de Boer RA, Maisel A, Cleland JGF, Kozhuharov N, et al. Heart Failure Association of the European Society of Cardiology practical guidance on the use of natriuretic peptide concentrations. Eur J Heart Fail 2019;21:715-31.

12. Santema B, Kloosterman M, van Gelder IC, Mordi I, Lang CC, Lam CSP, et al. Comparing biomarker profiles of patients with heart failure: atrial fibrillation vs. sinus rhythm and reduced vs. preserved ejection fraction. Eur Heart J 2018;39:3867-75. 